\title{
3. Data mining: Indigenous peoples, applied demography and the resource extraction industry
}

\section{John Taylor}

In recent decades, applied demography has emerged as a sub-field of demography partly in response to a growing demand from governments and private sector interests to better understand the implications of population trends for public policy and business strategy (Murdock and Ellis 1991; Siegel 2002). While in essence, this involves the practical application of demographic materials and methods (Siegel 2002: 2), the emphasis is on gaining knowledge of the consequences and concomitants of change in the size of populations, their distribution, composition and characteristics, so as to guide decision-making related to planning and the distribution of public or private sector goods and services for current and future use (Murdock and Ellis 1991: 6). This is precisely the empirical input that industry, government and Indigenous stakeholders have begun to identify as contributing to meaningful discussions about options for integrating the activities of mining operations with broader social and economic development goals in mine hinterlands. Accordingly, a push for profiling regional social and economic conditions has emerged from a coalition of these interests (Harvey and Brereton 2005).

Underlying this push, the current political economy of minerals development across remote Australia attempts to ensure that Indigenous peoples and communities increase their capacity to participate in bouyant regional economies that are stimulated by the 'super-cycle' of global demand for mineral products (Harvey 2002a; Hooke 2007). Overall, the aim is to establish initiatives that will secure sustainable economies for mining regions beyond the operational life of mines, making full use of local labour (Harvey 2002a, 2004). From a minerals sector perspective, this reflects the growing influence of corporate social responsibility and a corresponding recognition of necessary foundations for a social licence to operate (Trebeck, Chapter 6). From an Indigenous perspective, it reflects the assertion of a legitimate stake in directing regional development options, not least on Aboriginal lands. And from a government perspective, it reflects a window of opportunity to realise policy goals of Closing the Gap via the activities and economies of scale induced by minerals development.

\section{Measuring impacts}

One way in which these varied aspirations are pursued is through negotiated mining and other region-specific agreements. In the early 1970s, there was 
considerable optimism that mining agreements, many with significant financial benefit packages, would make a difference to the marginal economic situation of Indigenous beneficiaries (Altman 1983). However, research to date indicates that for a complex set of reasons, Indigenous economic status has changed little in subsequent years - dependence on government transfer payments across remote Australia remains high, while the economic profile of Indigenous people residing in the vicinity of major long-life mines is often indistinguishable from that of Indigenous people elsewhere in remote Australia (Taylor 1999, 2003; Taylor and Scambary 2005).

This situation partly reflects the incapacity of Indigenous community organisations and individuals to cope with the impacts of large-scale operations and take advantage from them. Equally, though, such organisations and the people they represent may have ambivalent responses to the potential cultural assimilation implied by their increasing integration into a market economy and its associated monetisation of many aspects of social life. A third key factor has been the attitudes and responses of both mining companies and governments, and their inability to comprehend and respond to the scale of historic Aboriginal disadvantage and strain on the social fabric of societies so radically affected by colonisation.

As well as these issues, it is now also clear that the content of many agreements has been far from optimal and that substantial legal, policy and institutional obstacles remain in the way of favourable negotiated terms related to mining activity on Aboriginal lands (Altman, Chapter 2; O'Faircheallaigh 2006). One issue in particular that has compromised the quality (or effectiveness) of agreements, is the general lack of attention paid to initiatives and activities required to give effect to stated provisions. The result, in many instances, is a failure of implementation for want of adequate resources and structures to ensure that this occurs and is sustained ( $\mathrm{O}^{\prime}$ Faircheallaigh 2002a).

Viewed historically, this general failure of agreements to monitor progress and impacts may be seen as a lesson once learnt, then subsequently lost, since the prototype for monitoring emerged as a key recommendation of the Fox Inquiry as far back as 1977. This inquiry called for the establishment of a five-year monitoring study of the social impact of uranium mining on Aborigines that was undertaken by the Australian Institute of Aboriginal Studies. While this study openly eschewed what it referred to as the 'technocratic tradition' and the hard-edged statistical approach of the policy sciences, it nonetheless aimed to generate as much baseline data as possible against which to measure social change. In line with a movement towards what was described as a 'political' or 'community development' model of social impact assessment (Ross 1990: 12), this was to be developed as a computer-based store of relevant information that could answer numerous questions for Aboriginal communities, government 
agencies, mining companies and researchers, and be functional for decades to come (Australian Institute of Aboriginal Studies 1984).

While the scope of this study was sound enough, it is interesting to note that almost 20 years later when faced with the task of profiling the employment, income, education, housing and health status of the Aboriginal population in Kakadu National Park and acquiring some sense of how these might have changed over the previous 20 years, the Kakadu Region Social Impact Study had no readily available and comprehensive statistical information upon which to determine its case. This was due to a failure of the Australian Institute of Aboriginal Studies study to provide adequate quality data for the regional population, even as a baseline, let alone in the form of ongoing monitoring that was initially called for (Kesteven 1986).

Partly in response to such issues, and in the emerging context of corporate social responsibility, there has been a concerted effort in recent years by some major mining companies to address aspects of this regional information void with support for regional profiling in the East Kimberley (Taylor 2004a), the Pilbara (Taylor and Scambary 2005) and the West Kimberley (Taylor 2006b). Wider recognition of this requirement by Indigenous stakeholders is also indicated by land council and native title representative body support for such activity in the case of the Kakadu Social Impact Study (1997b), as well as in the regional studies listed above.

Such profiles are an important adjunct to the formulation and subsequent monitoring of company and Indigenous stakeholder actions designed to increase Indigenous participation in regional economies. Specifically, they help in three ways: by establishing the quantum of needs for regional planning (both present and future), by identifying particular opportunities and constraints for enhanced participation in regional economies, and by providing the demographic backdrop for assessment of the effectiveness of any actions undertaken, whether this is done using conventional or alternative approaches to the evaluation of outcomes from mining agreements (O'Faircheallaigh 2002b: 18-22).

Furthermore, with a focus on the demographic composition and population dynamics of mine hinterlands, regional profiles can assist in the identification of targets to meet particular objectives, particularly in providing an overall sense of the scale of potential undertakings. This adoption of targets for improving the situation of Indigenous peoples is an issue that has recently drawn the attention of the Aboriginal and Torres Strait Islander Social Justice Commissioner in discussions over the Australian government's reporting framework on Indigenous disadvantage (Calma 2005). Casting this in a human rights approach, the argument presented is for accountability in moving towards the achievement of identified goals within a defined time frame. In development discourse this invokes the principle of 'progressive realisation' and takes reporting to a new 
level by requiring that stakeholders make justification if there is no improvement in certain agreed benchmarks, or where there is improvement, to establish whether the progress achieved is at a sufficient rate (Calma 2005). While the levels and rates involved to assess such progress require regular calibration, fundamentally they require the development of a baseline from which to measure change.

\section{Data on Indigenous populations in proximity to mining operations}

The Minerals Council of Australia (MCA) estimates that 60 per cent of mining operations in Australia are 'neighbours' with Indigenous communities (MCA 2004: 5). To this extent, the prospect of broad-scale demographic analysis is invoked. However, any consolidated approach to the demography of Indigenous populations in proximity to mining operations would belie the variable availability, quality and applicability of population data, to say nothing of the diversity of social, economic and cultural conditions that exist across mining regions. The very existence of estimated different land use agreements referring to distinct population groups and regional configurations demands disaggregated analysis. However, as we shall see, some geographic scaling-up is also required because of the nature of data availability and the relatively small size of population groupings.

\section{Population data}

Two categories of population data are necessary to support the different roles required of regional demographic profiling. The first concerns data for monitoring as enabled by the provision of a statistical baseline of existing conditions against which an assessment of past and future change can be made. The second supports a predictive role, or at least an anticipation of the possible effects of proposed development set against future population scenarios. In constructing such profiles, a range of data are available from a variety of published and unpublished sources including the Census of Population and Housing and other Australian Bureau of Statistics (ABS) collections, administrative data sets held by Commonwealth and State government agencies, and statistical information from mining companies, regionally-based institutions, and Indigenous organisations. The array of such available data is substantial and some idea of the range, even for relatively small geographic areas, is provided in Table 3.1, based on experience in the Thamarrurr region of the Northern Territory (Taylor 2004a).

To date, regional profiles have involved the development of social indicators drawn from across the range of official data sets as shown in Table 3.1. For both Indigenous and non-Indigenous populations, these include demographic structure and residence patterns, labour force status, education and training, income, welfare, housing, justice and health status. Ideally, indicators for each of these 
categories should be established at the commencement of local mining operations and then subsequently in order to establish trends. To complete the profile, regional population projections should also be produced, typically for 20 years (roughly a generation). This may encourage forward thinking and an anticipation of needs - and the opportunity to respond to them before they are realised. Whilst acknowledging that the accuracy of projections diminishes with the length of projection period (Bell 1992; Smith and Sincich 1991), this capacity to project future population levels is an essential component of the preparation of regional profiles. All too often in Indigenous affairs, policy has been 'reactive', and by responding to historic levels of need thereby creating a constant sense of catch up. If mining agreements are to be effective catalysts for change what is required is a 'proactive' methodology which seeks to anticipate and plan for expected requirements - essentially a means of translating the content and intent of agreements into a required quantum of program and partner commitments over a given time frame.

\section{Data quality}

In establishing the relative social and economic circumstances of Indigenous and non-Indigenous Australians, there is considerable reliance on census data for many key indicators. This has a number of advantages given the comprehensive scope of coverage and the application of standard measures. However, there are drawbacks too. First of all, the five-yearly census means that available population data can be as much as seven years old when first publicly available, given the time taken to process census output. There is also the problem of coverage, both in terms of population counts and population characteristics, especially for the Indigenous population. To date, the net census undercount of Indigenous peoples has been estimated to be around 6-7 per cent, although this is likely to vary geographically, with much higher rates estimated for some remote regions (Martin and Taylor 1996; Taylor and Bell 2003). The application of a post-enumeration survey by the ABS in remote Indigenous communities for the first time in 2006 produced substantial estimates of net undercount of 24 per cent, 19 per cent and 12 per cent respectively in the Northern Territory, Western Australia and Queensland (ABS 2007). Non-response to census questions is also an issue (Taylor 1993), with relatively high rates of non-response observed for many Indigenous population characteristics. While little can be done about non-response for census characteristics, the ABS does establish post-censal estimates of the Indigenous population in an attempt to adjust for undercount and non-response to the Indigenous status question, and herein lies a solution to the problem of coverage raised above. 
Table 3.1 Data items available for the Thamarrurr region from Commonwealth, Northern Territory and local government agencies

\begin{tabular}{|l|}
\hline Population \\
\hline $\begin{array}{l}\text { ABS census counts and estimates of Indigenous and non-Indigenous population by } 5 \text { year age and sex for } \\
\text { Wadeye town and outstations as a group. }\end{array}$ \\
\hline $\begin{array}{l}\text { Community census producing single year Indigenous and non-Indigenous age and sex capable of manipulation } \\
\text { by community working groups into section of town, individual outstations, and clan groupings. }\end{array}$ \\
\hline Clinic estimate of 'active client' Indigenous and non-Indigenous population by 5-year age and sex \\
\hline Thamarrurr Housing Office population list of service population \\
\hline Age and sex of Centrelink customers \\
\hline Age and sex of regional residents on the electoral roll \\
\hline Number of Indigenous persons registered with Medicare with a usual address in Thamarrurr \\
\hline
\end{tabular}

\begin{tabular}{|l|}
\hline Labour force \\
\hline Census data on labour force status, industry, occupation, hours worked \\
\hline CDEP $^{b}$ participants by age, sex, and occupation \\
\hline Centrelink data on Newstart and Youth Allowance payments \\
\hline Local employer administrative records \\
\hline
\end{tabular}

\section{Education and training}

School enrolments by age, sex and grade level

School attendance by age, sex and grade level

School Multi Level Assessment Program (MAP) test results for Year 3 and 5 reading and numeracy

Enrolments: by training provider category by field of study by certificate level and accreditation category by outcome status by Indigenous status, age and sex

Census data on highest level of schooling achieved

Census data on post-school qualifications

\begin{tabular}{|l|}
\hline Housing \\
\hline Census estimates of housing occupancy rates \\
\hline CHINS $^{\text {a }}$ and census data on housing stock by occupancy and number of bedrooms \\
\hline CHINS data on housing stock by repairs needed \\
\hline CHINS and census-based estimates of housing need \\
\hline
\end{tabular}

\begin{tabular}{|l|}
\hline Health \\
\hline Chronic disease incidence by age and sex \\
\hline Growth characteristics of under-5s \\
\hline Regional food costs compared to elsewhere in NT \\
\hline Cost of family food basket \\
\hline Fresh food variety, quality, availability \\
\hline Unique hospital patients by Major Diagnostic Code (MDC), 5 year age and sex \\
\hline Hospital patient separations by MDC by 5 year age and sex \\
\hline Birth weights \\
\hline Active client population for clinic by 5 year age and sex \\
\hline Clinic staffing classification by Indigenous status \\
\hline
\end{tabular}

\begin{tabular}{|l|}
\hline Justice \\
\hline Reported regional property offences and offences against the person \\
\hline Persons in adult correctional centres by last known address and birthplace \\
\hline Juveniles in detention by last known address and birthplace \\
\hline Adult conditional liberty caseload \\
\hline Juvenile conditional liberty caseload \\
\hline Conditional liberty order commencements \\
\hline
\end{tabular}




\section{Welfare}

Centrelink payments by type and \$ amount (cells $<20$ supressed)

Census estimates of employment and non-employment income

a. CHINS = Community Housing and Infrastructure Needs Survey.

b. $\mathrm{CDEP}=$ Community Development Employment Program.

Source: Taylor 2004b.

Basically, in situations of significant undercount, the census can be viewed as a very large sample survey with the key output being population rates rather than population levels (Siegel 2002: 495). Rates established net of non-response (on the assumption that the latter are evenly distributed for each population characteristic) can then be applied to population estimates-initially to the estimate for the census year, and then to any population projections from the census year on the assumption that the observed rates remain constant or change according to prescribed criteria. While an assumption of constancy might be seen as unrealistic, it should be noted that one of the unfortunate features of many Indigenous social indicators in mining regions over the past two decades (such as labour force status, income, education, and housing) has been their relative stability. It is also true that social indicator rates, by their very nature, are unlikely to drastically alter over short periods of time as they require substantial shift in levels in order to effect change (Hunter 1999). This is especially so among rapidly growing populations.

Whatever the approach to constructing regional profiles, it is crucial that they are based on reliable population estimates. Program-wise, this requires reliable breakdown into relevant policy age-groups: infants, mothers, school-age children, youth, young adults, middle-aged, and older people. Ideally, it also requires that statistical events in the population (such as employment numbers, school enrolments, hospital separations) are drawn from the same population universe, such that numerators are drawn from denominators in the calculation of rates. Unfortunately, under conditions of high inter-regional mobility and variable reporting of Indigenous status in administrative systems, this is not always the case (Cunningham 1998). What is clear, though, is that standard small area statistics as available from the ABS in the form of Indigenous Community Profiles provide only a starting point. Not only do these require ground-truthing in terms of cultural and geographic match, they are also limited in scope (and sometimes coverage), hence the need for additional data to be compiled from alternate sources.

Perhaps more telling from the point of view of data quality are concerns about the capacity of official data to provide a meaningful representation of the social and economic status of Indigenous people, especially in remote regions. Is it meaningful to measure one set of social, cultural and economic systems (Indigenous/local) using the tools, methods, and purposes of another (mainstream/national/global)? One view on this describes the process of census 
enumeration in remote Aboriginal communities as a 'collision of systems' and concludes that census questions lack cross-cultural fit and produce answers that are often close to nonsensical (Morphy 2002). Equally, while social indicators report on observable population characteristics, they reveal nothing about more behavioural population attributes such as individual and community priorities and aspirations for enhancing quality of life. Indeed the whole question of what the latter might mean and how it might be measured for Indigenous populations is only now being addressed by the United Nations Permanent Forum on Indigenous Issues in challenging the appropriateness of Millennium Development Goal indicators (United Nations 2006), an issue that has also been raised in the context of Australian frameworks for reporting disadvantage (Taylor 2008a). In working through these questions, we should be mindful that from an Indigenous perspective the very notion of measurement often carries with it the spectre of state control, and the implications of who is measuring what, for whom, and to what end should be crucial points for consideration, as demonstrated, for example, in respect of Maori (Smith 1999).

Thus, regional profiling using official statistical data can be seen simply as a method for 'rapid appraisal' and rightly criticised for lacking community input, thereby restricting its relevance and representativeness (Birckhead 1999; Walsh and Mitchell 2002). The danger is one of using data that have little relevance (to Indigenous stakeholders) and excluding those that do. Thus, along with the compilation of mainstream social indicators there is a need also to acquire information that reflects Indigenous priorities and understandings of what constitutes appropriate and sustainable development. This has some resonance with O'Faircheallaigh's (2002b) 'alternate' approach to evaluation which includes examination of the unfolding responses of Aboriginal actors to development initiatives. So far, however, only limited attempt has been made to incorporate such data into regional profiling (Taylor and Scambary 2005), although Scambary (this volume) has explored Indigenous development aspirations in considerable ethnographic detail and found these to be often at odds with more mainstream understandings of optimal outcomes from the interaction between miners and Indigenous people. Likewise, in a survey of traditional Aboriginal owners conducted in 2006 to establish what they wanted to do with their land, less than 13 per cent listed economic development as a first priority while more than one-third highlighted access, residence, land and sea management and cultural heritage (Balsamo and Calma 2007). Interestingly, these are all components of what O'Faircheallaigh (2006: 3-4) has referred to as the 'better life' that many Aboriginal people aspire to while living on land that they own. Partly for these reasons, the extent to which data of sufficient quantity and quality currently exist in Australia exist for the purposes of establishing meaningful baseline profiles remains a moot point. 


\section{Indigenous culture and measurement}

A recent study of social and economic conditions in the Pilbara sheds some light on this issue (Taylor and Scambary 2005). This study sought the views of a selection of local Aboriginal people on conventional social indicators that were deemed to be representative of their parlous socioeconomic situation. One such comment reflecting on increasing levels of participation in mining employment was as follows:

"Life is a bit better out here because of mining and those agreements. But my thing is my own kids, we're not pushing them into what we want them to be. It's up to them as individuals, I believe that's fair enough. They can go and work in the mine, but they will be men and will have kids of their own, and they need to be there for their own kids to learn and teach them their culture. Because it's about carrying on the traditional cultural ways teaching knowledge skills, and the country itself, all those kinds of things, the trees, the language, going to ceremony, going out on country. My kid's father is teaching our kids. His grandmothers and grandfathers, they passed on all the knowledge to him, making him understand who he is, he hasn't missed out on anything, he's got it all and he knows what his role is as a cultural man and in our cultural life. But some of those mining men aren't there for all that and that's no good." (Taylor and Scambary 2005: 58)

This statement has relevance for any discussion about the evaluation and monitoring of mining impacts. It highlights the fact that a positive mainstream measure of development (employment in mining) may have negative consequences for an Indigenous measure of well-being (carrying on traditional cultural ways). More to the point, it illustrates that a range of Indigenous views on the appropriateness of various indicators are likely to exist and that these may stand outside, and therefore be excluded from, mainstream indicator frameworks.

Not surprisingly, then, a consistent message to emerge from consultations conducted by the Australian Government with select Indigenous people and organisations regarding the measurement of disadvantage is the need to improve representations of Indigenous culture in formal reporting frameworks (Steering Committee for the Review of Government Service Provision 2005: 2.11). Although no explanation is provided as to what precisely is meant by the term 'culture' (Peterson 2005), a basic dilemma to emerge from these consultations is the difficulty of identifying single indicators given the diversity of Indigenous circumstances and societies across Australia. Furthermore, the fact that the construction of objective indices is more likely to be directed at informing government policy, and not necessarily Indigenous priorities and processes, means that the challenge is to satisfy the first requirement while at the same 
time producing measures that have widespread relevance to Indigenous peoples. Ultimately what is sought, then, is similar to the mechanism for illuminating the legal nature of native title for public discourse in Australia in terms of a 'recognition, or translation, space' that exists where Indigenous law and custom and Australian property law intersect (Mantziaris and Martin 2000). This conceptualisation of a legal 'recognition space' may be adapted to the area of social indicator development as illustrated in Fig. 3.1.

As inferred from the diagram, much of what constitutes important aspects of Indigenous world views, notions of productivity, appropriate structures of social relationships, land relationships, kinship rights and obligations, reciprocities and accountabilities (Altman 2005a; Martin 1995; Peterson 2005; Povinelli 1993; Schwab 1995; Trigger 2005) - in effect, different ways of life - is not necessarily brought to the level of public discourse (the intersect in Fig. 3.1), and is therefore not easily amenable to measurement. Even where measurement appears possible, distinct modes of Indigenous living and aspiration may be incommensurate with the broad goals of government policy to the point where they defy common understandings.

\section{Fig. 3.1 The potential recognition space for indicators of Indigenous well-being}

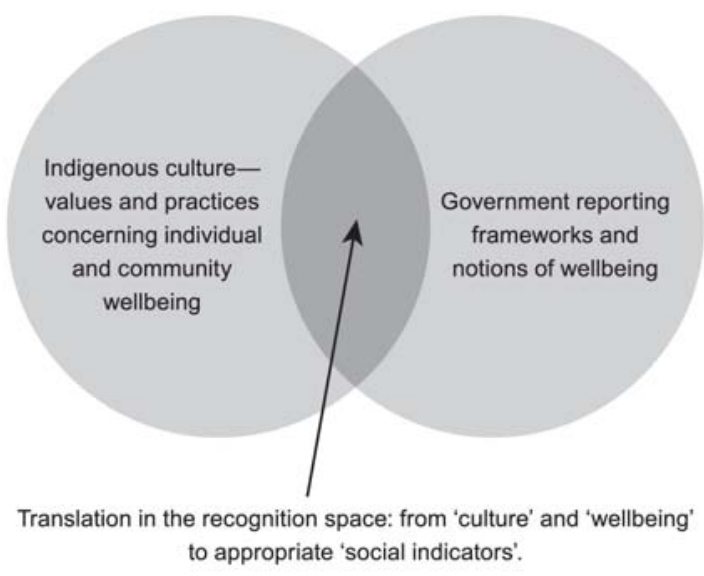

Source: Taylor 2008c.

In the Australian context, for example, there is a clear contradiction between the desire of many Indigenous people to live in remote areas in small dispersed communities on traditional lands, and the general thrust of government policy intent on securing Indigenous participation in mainstream urban economies as a core means to enhance well-being. By the same token, elements of government reporting (certainly when it comes down to particular strategic change measures) may have little connection to Indigenous concerns and practices. An especially poignant example of this is provided by outputs from the Australian census which, because they are designed to represent the circumstances of mainstream 
Australia, generate results for Indigenous peoples in remote settings that can have little meaning (Morphy 2002). As noted earlier, important elements of Indigenous customary economic activity, for example, can be overlooked entirely (Altman 2005a, 2007b; Altman, Buchanan and Biddle 2006), a problem noted for other Indigenous populations in developed country settings (Usher, Duhaime and Searles 2003).

The main focus of the diagram, then, is on the overlap where policy makers and Indigenous people can seek to build meaningful engagement and measurement. This is the area that allows for a necessarily reductionist translation of Indigenous people's own perceptions of their well-being into measurable indices sought by industry and governments. What is captured in this space is obviously far from the totality of Indigenous understandings of well-being, a point noted before in respect of Australian social survey data (Peterson 1996). As Peterson (2005) has also pointed out, without a common agreed view of different and shared perceptions of well-being, the danger is that indicators become ethnocentric and the notion that Indigenous people may have their own life projects is obscured by the pressing moral and political objective of achieving statistical equality that comes with policies of closing the gap and mainstreaming (see also McCausland 2005b; Tehan et al. 2006: 7-8). In working through these questions, the implications of who is measuring what, for whom, and to what end is therefore crucial. This cross-cultural encounter involves more than just recognition of difference - it requires the development of models of bi-cultural or partnership research involving negotiated design, methodologies and outcomes (Smith 1999: 173-8). According to the Aboriginal and Torres Strait Islander Social Justice Commissioner (Calma 2005), part of the means to this end lies in ensuring effective full participation of Indigenous people in all stages of data collection and analysis as an essential component of participatory development practice, much in the same way as has been achieved in New Zealand (Wereta and Bishop 2006).

In the sphere of economic activity alone, there is clearly scope within agreement-making processes to broaden the range of data within the area of overlap in Fig. 3.1 in a manner that better represents the priorities of Indigenous people. Indeed, it may be argued that agreement-making requires this (Tehan et al. 2006: 8). For example, if we return to the above quote from the Pilbara, then "carrying on traditional cultural ways" might be reflected in a range of economic activities associated with cultural and language maintenance, arts and crafts manufacture, land and sea natural resource management, and cultural tourism that are widespread across remote Australia (Armstrong, Morrison and Yu 2005; Hill et al. 2005; Toussaint et al. 2001). From a profiling perspective, the problem is that such activities are poorly quantified and often amorphously classified in labour statistics under the category 'Community Development Employment Program'. 
To take the West Kimberley region as a case in point, there are numerous examples of significant impacts on local economic participation that derive from Indigenous priorities for economic development - the trochus hatchery at One Arm Point, the Pandanus Park freshwater crustacean project, the Manbana multi-species aquaculture hatchery and discovery centre in Broome, the Emama Nguda mud crab fishing enterprise in Derby, Goolarri Media Knowledge Centre in Broome - numerous small cultural tourism enterprises across the region provide commercial examples of this. Elsewhere, land and sea management activities include the Dugong and Marine Turtle project on the Dampier Peninsula, the Saltwater Country project along the north-west Kimberley coastline, the Coastal Landcare project at Broome, the Karrajarri Coastal Management at Port Smith involving Karrajarri Rangers, the Freshwater Sawfish project on the Fitzroy River, and the Rivercare project based on the development of a Fitzroy River Action Management Plan. Alongside these are activities aimed at developing consolidated 'looking after country' plans across the region combining the resources of the Kimberley Land Council, the Kimberley Aboriginal Law and Culture Centre, the Kimberley Aboriginal Pastoral Association, and the Kimberley Language Resource Centre. An example of this was the establishment by Kimberley Aboriginal Law and Culture Centre and the Yiriman Project of a pilot community ranger program at the Jarlmadangah Burru Community in 2006 with options now being explored to extend training and employment pathways for Aboriginal Rangers along the lower Fitzroy River. Soon to come on stream within the Ngurrara Native Title claim is the Great Sandy Desert - Warlu Jilajaa Jumu Indigenous Protected Area with proposals for further ranger programs. Altogether, 11 ranger programs currently exist across the Kimberley under the umbrella of the Kimberley Land Council and North Australia Indigenous Land and Sea Management Alliance with most of these heavily reliant on Community Development Employment Program (CDEP) funding.

Despite all this activity, there is no clear sense of overall impact for want of an appropriate instrument for measuring the collective number and nature of jobs created and the degree to which these might be further developed and supported to form part of a broad-based sustainable regional economy. In this regard, it is significant to note substantial movement on the part of the Commonwealth government with the establishment of the Working on Country program for Indigenous employment in activities such as fire management, feral weed and animal control and heritage site protection.

\section{What hinterland? Defining the region}

A fundamental issue for regional profiling, and one that is likely to assume variable character depending on the nature of different agreements, is the question of precisely which population (and therefore which geographic area) is implicated. Consideration of this matter has its origins in the original 
deliberations over the receipt of mining monies from the Ranger mine and the relevant provisions of the Aboriginal Land Rights (Northern Territory) Act 1976 (Cwlth) (ALRA) that refer to 'areas affected'. While the political contestations in regard to this important matter are of interest in themselves, what concerns us here, with respect to profiling, is the outcome in relation to what ended up constituting the 'region' or geographic unit of analysis.

The Ranger case is instructive. Initially, 'the traditional owners of the Kakadu region' were to receive Ranger up-front monies (Levitus 1991: 156). While the 'Kakadu region' was not precisely defined, it was conceived as approximating Stage 1 of Kakadu National Park and the Ranger Inquiry land claim identified 107 people as the traditional owners of that area (Levitus 1991: 157). However, in creating an Association to hold dealings with traditional owners, the Northern Land Council adopted a more inclusive approach to compiling Association membership. As a consequence, by 1979, membership of the new Gagudju Association was much larger and comprised individuals, 'connected with the Ranger country, either through blood ties, intermarriage, clan relationships or some shared dreamings' (Levitus 1991: 157). By the mid-1990s, however, the Mirrarr Gunjeihmi clan challenged the validity of the Gagudju Association to receive 'areas affected' monies and legal opinion supported their view that the ALRA reference to area affected referred to the physical area of the Ranger mining lease rather to the spatially much wider notion of social affectedness (Altman 2007b, this volume Chapter 2).

All of this greatly complicates matters in terms of circumscribing a definitive geographic area for the purposes of regional profiling. It also shows that where there is intention to construct social indicators from secondary sources for a population defined on the basis of cultural criteria then this can be rendered difficult by the sort of ambiguities illustrated above. This aside, the fact that most official and administrative data are available at fixed aggregate levels only and mostly for relatively large areas (certainly beyond a mining lease area) results in a degree of inflexibility. In the Kakadu Social Impact Study, this area turned out to be that bounded by Stages 1 and 2 of Kakadu National Park as these matched ABS geographic boundaries (Taylor 1999). For the most part, then, the geographic areas for which statistical information is available (including administrative data) are dictated by the boundaries set out in the ABS' Australian Standard Geographic Classification (ABS 2006a) and the Australian Indigenous Geographic Classification (ABS 2002).

Accordingly, in profiling socioeconomic circumstances, the tendency has been to take a broad regional, rather than limited local, perspective on the geography of mine hinterlands. This is not just because of the sorts of issues raised above, but also because a key interest of some mining companies and Indigenous stakeholders is to build regional economies beyond the mine gate (Barker 2006; 
Harvey 2002a). One manifestation of this is the negotiation of Indigenous Land Use Agreements (such as the Argyle Participation Agreement) that can have effect over substantial geographic areas. In the lead up to this agreement, discussions with the Kimberley Land Council about what constituted the region of interest for baseline profiling focused initially on the area covered by the Good Neighbour Program involving communities closest to the Argyle mine site, but then this widened out to incorporate the whole of the east Kimberley excluding the southern part of Halls Creek Shire, but including Kalumburu (Taylor 2004a). Likewise, the Century Zinc Project Act 1997, enacted in relation to the Gulf Communities Agreement, referred to a large area known as the Carpentaria-Mt Isa mineral province. Such interpretations necessarily expand the scope of any analysis beyond the potentially narrow geographic bounds of immediate mine hinterlands to encompass more functional definitions of 'area affected' based on some measure of regionally integrated social, economic and administrative interactions. In the Pilbara, for example, the physical separation of most Aboriginal people from actual mine sites means that 'local' labour is likely to be drawn from across the whole of the ABS' Pilbara Statistical Division which more or less represents the jurisdiction of the Pilbara Native Title Service under the umbrella of the Yamatji Marlpa Barna Baba Maaja Aboriginal Corporation (Taylor and Scambary 2005).

Although regional perspectives clearly emerge in practice, what is lacking is any operational definition or criteria for guidance on regional selection, except to say that there seems to be some trade-off between regions identified according to customs and traditions versus the need for economies of scale and recognition of existing service delivery frameworks in development planning. This is captured by the Northern Territory Government's Stronger Regions Policy that initially envisaged negotiated regions based on the following criteria:

an area that the people in it see as a region and that the government agrees should be treated as such; where a reasonable community of interest exists; where there is capacity to achieve economies of scale in the achievement of outcomes; and where there is demonstrated capacity or need for whole of community action to cooperate in the achievement of shared objectives (Northern Territory Government 2003).

While such groupings might appear intuitively sound, it should be noted that complexities are almost certain to arise in seeking to establish boundaries for the purposes of representing regional 'communities of interest' with 'shared objectives'. Useful insights into the nature of such complexities and how they might impact on attempts at regional planning are available from Sutton's (1995) critique of Davis and Prescott's (1992) work on Aboriginal boundaries, and Morphy's (1999: 36) critique of the Reeves (1998) proposals for reform of the ALRA. 


\section{Indigenous population trends in Australia}

For the most part, Australian mineral provinces occupy large swathes of country across the remoter parts of the continent. In such areas, significant demographic shifts have been underway since colonisation although the defining feature of regional demography remains the high Indigenous share of population and the relatively high Indigenous rate of natural increase (Taylor, Brown and Bell 2006). By way of background, it is worth noting that parallels exist between the modern-day classification of remote areas and the historic distinctions drawn between 'colonial' and 'settled' Australia in recognition of the much higher proportions of Indigenous people in remote areas, and the somewhat different manner of their incorporation into wider social and economic structures (Rowley 1971).

This spatial framework also provides essential context for understanding the substantial transfer of land back to Aboriginal ownership across remote regions that has occurred in recent times, with the prospect of more to come via land purchase and successful native title claims (Altman, Buchanan and Larson 2007; Pollack 2001). One prominent long-term analyst of demographic trends in remote areas views this land transfer as an important element of the post-productivist transition in Australia's rangelands with newly recognised land values often lying outside the old economy, being more culturally-based (Holmes 2002). These values are manifest in the emergence of a distinct settlement structure on Aboriginal lands involving the formation of numerous, dispersed, small, Indigenous communities, especially in the Northern Territory, Western Australia and the far north of South Australia and Queensland. Most, if not all, of these communities required no modern economic base, nor have they subsequently acquired one, at least not in a manner beyond the combined provisions of a sizeable state sector, a limited private sector, and a customary sector of variable size. The term 'hybrid economy' has been coined to describe this structural arrangement (Altman 2005a). Across remote areas, a total of 1112 such communities were identified by the Community Housing and Infrastructure Needs Survey (CHINS) in 2006 with a total estimated usual population of 80,500 (ABS 2006b: 17). The vast majority (838, or 75 per cent) of these were very small in size with less than 50 persons, although collectively these very small places accounted for only 10,200 persons, or 13 per cent of the total in remote discrete communities (ABS 2006b: 5).

For reasons of differential population dynamics, the Indigenous population in remote parts of Australia grew by 23 per cent between 1981 and 2001 while overall non-Indigenous population growth over the same areas has been negative since 1986 (Taylor 2003). Away from the larger mining towns and service centres of remote Australia, Indigenous peoples are increasingly the majority. These trends are leading to a rising Indigenous share of remote area population and 
there is every reason to expect that this will continue. While there is no denying that minerals development has been a major stimulus to population growth in these areas since the 1960s, it is also true that this has been highly variable due to boom and bust in commodity prices, while part of the ongoing dynamic has been a distortion of underlying non-Indigenous population growth rates due to the expansion of fly-in-fly-out arrangements (Storey 2001).

Across the vast arid zone, the Indigenous population is projected to rise from 39800 in 2006 to 47000 in 2021 while the non-Indigenous population is projected to decline from 135000 to 124000 (Taylor Brown and Bell 2006) producing an increase in the Indigenous share of population in Arid Australia from 23 per cent to 27 per cent. In the combined regions across the wet tropics from Cape York to the Kimberley, similar projections to 2016 indicate a rise in Indigenous population from 25600 to 32400 representing an increase in population share from 38 per cent to 42 per cent (Taylor and Bell 2001). Even in the more economically dynamic remote regions of the outback, such as the Pilbara, the Indigenous share of the usually resident regional population is projected to continue to rise from 16 per cent in 2001 to 18 per cent by 2016 (Taylor and Scambary 2005). Some indication of the sorts of figures involved for Indigenous growth in selected mining regions is shown in Fig. 3.2 using 1996 Census based cohort-component projections, although ideally such projections would also be informed by economic impact forecasting (Phibbs 1989).

\section{Employment implications of Indigenous population growth}

Given that commitments to Indigenous employment and training form a key part of many mining agreements, one of the key implications of this high Indigenous population growth is the manner in which it interacts with labour demand and supply. In recent years, the thrust of both government and minerals sector policy has been towards increasing Indigenous employment in mainstream jobs. If we take an historic view of this we can see that while the numbers of Indigenous people employed in mining regions may have increased over the past 30 years or so, the rate has not because of a failure of jobs growth to keep pace with population growth. What then is the scale of the task ahead if the aim is to increase the rate of Indigenous employment? To establish this, we can use the projection of the future size of the working age population and consider this against variable scenarios in terms of regional employment rates. 


\section{Fig. 3.2 Indigenous population projections 1996-2016 in selected mining regions}

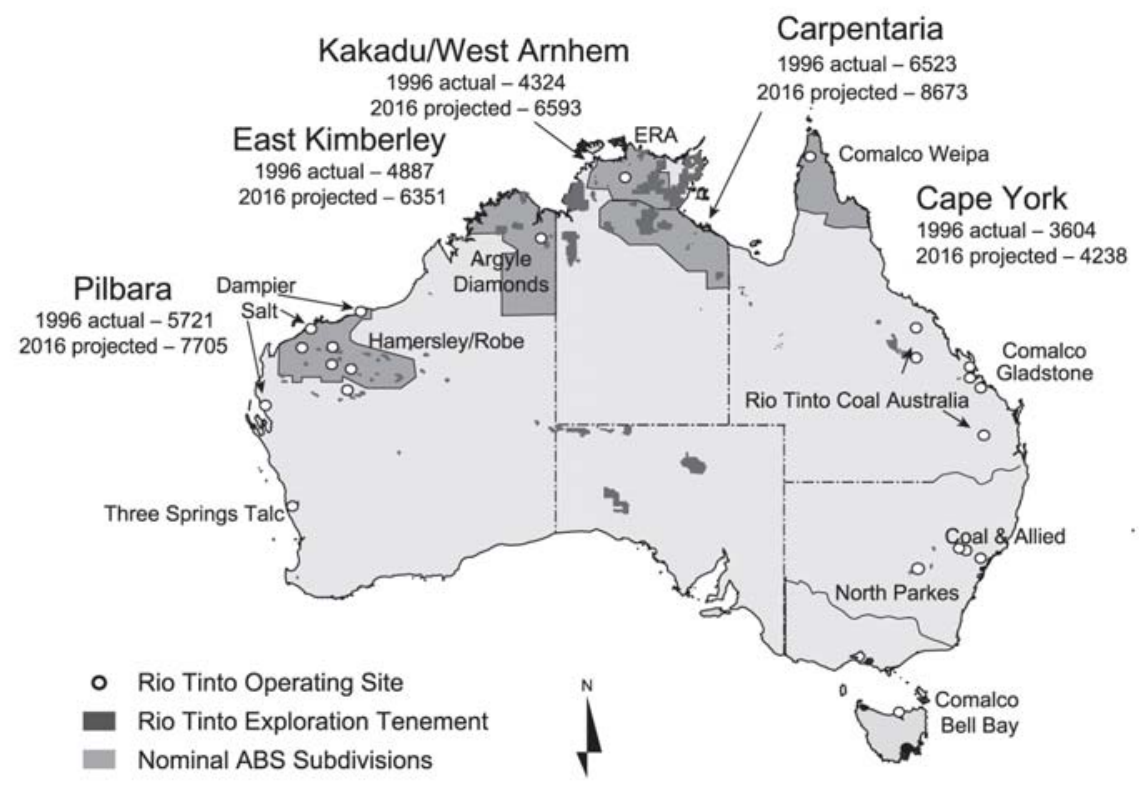

Source: Harvey and Brereton 2005.

The West Kimberley region provides a useful example. By 2021, the Indigenous adult population of the West Kimberley is projected to increase by 36 per cent (or an average of 2.1 per cent per annum) to reach a population of 9156-an increase of almost 2500 persons. What are the implications of this growth for future jobs needs if certain employment rates are to be achieved? Two scenarios are explored in Table 3.2. The first considers the number of Indigenous jobs that would be required in the West Kimberley by 2021 if the 2006 Indigenous employment/population ratio were to remain unchanged at 53.5 per cent (inclusive of CDEP). The answer is 4898 jobs, or an additional 2 381. The second scenario considers the future job requirements necessary to raise the Indigenous employment/population ratio to that recorded for non-Indigenous residents (79.3 per cent). This requires the number in work to reach 7261 - massively in excess of the current level. In effect, to close the regional employment gap with the non-Indigenous workforce, the number of Indigenous people in work across the West Kimberley would need to almost triple over the next 15 year period, with an additional 316 jobs created and then occupied each year. 
Table 3.2 Extra Indigenous jobs required in the West Kimberley by 2021

\begin{tabular}{|l|c|c|c|}
\hline Employment/population ratios in 2006 & $\begin{array}{c}\text { Base employment } \\
\mathbf{2 0 0 6}^{\mathbf{c}}\end{array}$ & $\begin{array}{c}\text { Total jobs required by } \\
\mathbf{2 0 2 1}^{\mathbf{c}}\end{array}$ & $\begin{array}{c}\text { Extra jobs required by } \\
\mathbf{2 0 2 1}\end{array}$ \\
\hline $53.5^{\mathrm{a}}$ & 2517 & 4898 & 2381 \\
\hline $79.3^{\mathrm{b}}$ & 2517 & 7261 & 4744 \\
\hline
\end{tabular}

a. The Indigenous census-derived employment/population ratio in 2006 inclusive of CDEP.

b. The non-Indigenous census-derived employment/population ratio in 2006.

c. Based on projections of Indigenous adult population by 2021 (9156).

Source: Taylor 2006b.

\section{Implications for government and industry}

As noted at the outset, the role of applied demography is to provide an essential quantum to discussions of needs, aspirations, and policy development. The basic message conveyed from such applications to date in mining regions across northern Australia is that little had been achieved over the decades since mining commenced in terms of enhancing overall Indigenous socioeconomic status, and that this is now exacerbated by rapid population growth. Despite current unprecedented demand for Indigenous labour in the formal economy, the capacity of labour to respond to this remains substantially constrained by limited human capital. As a consequence, many in the Indigenous population will continue to experience structural dis-engagement from mainstream work in the absence of substantially enhanced infrastructure and services to redress historic exclusion.

Of course, in pursuit of a social licence to operate, major corporates are active in engaging Indigenous workers with many mine sites adopting target quotas. But such is the depth of supply-side disadvantage that a major challenge lies ahead in meeting these targets (certainly in a collective sense) given that they are likely to come close to exhausting entire local supplies of employable labour. For this reason, companies are increasingly investing in remedial programs to enhance work readiness and to address structural barriers in meeting 'fitness for work' requirements (Tiplady and Barclay 2007). Even so, if current targets were to be achieved, the additional jobs created might only suffice to keep pace with the growth in the Indigenous working-age population. Thus, while much might be accomplished by the mining sector in the years ahead in terms of raising levels of Indigenous employment, little change might be discernable in terms of aggregate social indicators, with a large component of the population remaining marginalised. To avoid this, it is essential that all sectors of regional economies should be utilised for Indigenous engagement, including activities associated with Indigenous priorities and aspirations in arts and craft manufacture, land and sea resource management, and cultural tourism. However, whatever development options are pursued, substantial constraints on participation remain to be overcome across the spectrum of social and economic conditions.

To indicate the scale of some of these constraints that have been quantified, Table 3.3 provides indicative proxies of labour force exclusion in the Pilbara 
for 2006. It is necessary to bear in mind that the adult population for that year was projected to be 4,759 . What this shows is that the vast majority of Indigenous adults in the region do not have full schooling; or a qualification; around half of adults remain outside the labour force; many are hospitalised at any one time; others are subject to chronic conditions requiring strict management regimes; many are arrested and incarcerated (especially young males); and feeding into this adult realm are relatively low achievers from the education system. In any event, the potential for prolonged and productive workforce participation on the part of young people is severely curtailed by premature mortality.

Table 3.3 Summary indicative proxies of Indigenous labour force exclusion, Pilbara region, 2006

\begin{tabular}{|l|r|}
\hline Population aged 15+ & 4759 \\
\hline Has no post-school qualification & 4200 \\
\hline Has less than Year 10 schooling & 1500 \\
\hline Not in the labour force & 2190 \\
\hline Hospitalised each year (all persons) & 2800 \\
\hline Has diabetes (25 years and over) & 1020 \\
\hline Has a disability & 1020 \\
\hline Arrested each year & 1050 \\
\hline In custody/supervision at any one time & 310 \\
\hline Achieves Year 7 literacy (current attendees) & $60 \%$ \\
\hline 15 year olds surviving to age 65 & $<50 \%$ \\
\hline
\end{tabular}

Source: Taylor and Scambary 2005.

From a policy perspective, levels of economic exclusion on the scale implied here raise questions about the adequacy of government resourcing to meet the backlog of disadvantage that has so obviously accumulated in many mining regions. Looking ahead, this raises questions about the costs to industry, to government, and to Indigenous people, if social and economic conditions remain the same as currently experienced. Basically, these costs will simply escalate in line with the growth in population. However, to properly assess adequacy in this context, it is not sufficient to consider amounts expended by governments on Indigenous programs separately from the key questions of whether such amounts are commensurate with the scale of the task of overcoming disadvantage, and whether they are equitable on a per capita basis when compared with spending in the States and Territories and nationally on people in similar circumstances.

It is interesting to note that the only analysis to have measured spending in this way for a single Aboriginal community (Wadeye) in the Northern Territory uncovered gross inadequacies and inequities in crucial areas of capacity building such as education, training and infrastructure with associated high expenditures in health, welfare and incarceration (Taylor and Stanley 2005). If similar inadequacies were to exist in communities across mining regions, and at this stage this is not known, then the level of government intervention aimed at 
overcoming disadvantage among the growing Indigenous populations of these regions would not only be found wanting, it would simply be 'funding into a deficit' (Ah Kit 2004). This reflects the regressive nature of the link between demography and economy in contemporary Indigenous Australia and it means that governments, and industry for that matter, can either invest up-front to build capabilities, or pay heavily in the future to manage the social and economic consequences. Whatever the case, a fiscal response is unavoidable.

\section{Conclusion}

With approximately 18 per cent of the Australian continent under some form of Indigenous tenure (Altman, Buchanan and Larson 2007), and with this set to rise via native title determinations and land purchases, the demand for statistical information on Indigenous groups as proprietors of territory is also growing in the context of formal agreement-making. As with the broader government agendas of closing the gaps, applied demography has found a natural and successful disciplinary niche here by exploiting the rich seams of census, survey and administrative data that make up the burgeoning Indigenous statistical archive, even at local and regional levels. In particular, it is the predictive capacity of the demographic repertoire that has mostly caught the eye of regional stakeholders (Harvey and Brereton 2005) with its fiscal opportunity-cost message that business as usual is simply not an option in Indigenous affairs because of the weight of population momentum. However, there are two important constraints on the efficacy of this contribution that need attention if the interests of Indigenous stakeholders are to be truly represented and if the scope of applied demography is to be extended.

The first of these relates to geography and concerns the long-standing conundrum of determining which area/peoples are affected/implicated by mining. In regard to this, it remains the case that analysts are constrained by the configuration of official ABS and other administrative boundaries that are used for the collection and dissemination of official statistical data. While it is true that the Australian Indigenous Geographic Classification of the ABS attempts to best reflect the spatial distribution of the Indigenous population - to enable a 'demography in situ' as it were (to use Kreager's (1982) term describing demography built from the ground upwards) - in some ways this misses the point entirely. The primary organising principles of Indigenous social formation are both spatial and socio-relational (Morphy 2007) and these invariably do not coincide to produce discretely bounded social groupings that neatly mesh with units of the Australian Indigenous Geographic Classification. In a nutshell, the statistical geography available to analysts is unlikely to provide a demography of Indigenous polities with rights and interests in particular places, or agreements.

In many ways this highlights an important distinction raised by Rowse (2008) between Indigenous populations and Indigenous peoples. Our current 
demography refers to Indigenous populations revealed by standard identification questions and is best suited to the provision of citizen rights. What it does not necessarily provide for are the interests of groups of Indigenous people in proprietory rights, in particular over areas of land. All across Australia we are witnessing a growing discrepancy between the best-intentioned of statistical output frameworks and the actual needs of Indigenous land-holding groups for an ethnographically-informed demography suited to their aspirations for managing the Indigenous estate via land use agreements.

The second constraint refers to the nature of available data themselves. While information on vital demographic events are constrained only by the degree to which this is gathered in respect of any population, the greater concern is to do with information on population characteristics as well as broader epistemological questions surrounding notions of well-being and what these imply about appropriate variables to be measuring. As things stand, the social, economic, and even some cultural, features of Indigenous populations are invariably established via mainstream categories. Whether these coincide with Indigenous categories in any given situation, and whether such categories can be identified, measured and are desired, remains a moot point. 